\section{KOMPARASI ADAPTASI BENCANA BANJIR DI KAWASAN WATERFRONT SUNGAI KAPUAS (PONTIANAK) DAN SUNGAI KAKAP}

\author{
Bontor Jumaylinda Br. Gultom ${ }^{1 *}$, Dian Rahayu Jati ${ }^{2}$, A Andi ${ }^{1}$ \\ ${ }^{1}$ Program Studi Arsitektur, Universitas Tanjungpura, Pontianak \\ ${ }^{2}$ Program Studi Teknik Lingkungan, Universitas Tanjungpura, Pontianak \\ JL. Prof. Dr. H. Hadari Nawawi - Kode Pos: 78124
}

\author{
Jurnal Pengembangan Kota (2020) \\ Volume 8 No. 1 (12-22) \\ Tersedia online di: \\ http://ejournal2.undip.ac.id/index.php/jpk \\ DOI: $10.14710 / j p k .8 .1 .12-22$
}

\begin{abstract}
Abstrak. Kawasan Waterfront Seng Hie dan Kawasan Waterfront Kakap merupakan kawasan waterfront yang sering dilanda bencana banjir rob tahunan. Ancaman ini tidak membuat penduduk pindah melainkan beradaptasi dengan bencana tersebut. Kedua lokasi ini memiliki batas alam dan sumber daya yang berbeda. Tujuan dari penelitian ini adalah untuk lihat perbedaan tindakan adaptasi bencana yang dilakukan oleh masyarakat pada dua lokasi yang memiliki kondisi yang berbeda. Metode yang digunakan dalam penelitian ini adalah metode concurrent embedded dengan model metode kualitatif sebagai metode primer (dominan) dan kuantitatif sebagai metode sekunder. Teknik pengumpulan data dalam penelitian ini dilakukan dengan teknik triangulasi (kualitatif) teknik kuesioner (kuantitatif). Hasil dari penelitian adalah ditemukan bahwa bencana yang sejenis yaitu banjir akibat air pasang tinggi terjadi di dua lokasi tetapi skala bencana di Kawasan Waterfront Kakap lebih ekstrim. Sedangkan dari segi tindakan adaptasi, di Kawasan Waterfront Seng Hie masyarakat melakukan tindakan yang sejenis, sedangkan di Kawasan Waterfront Kakap tindakan adaptasi yang bervariatif.
\end{abstract}

Kata Kunci: Komparasi; Adaptasi Bangunan; Adaptasi Perilaku; Banjir; Waterfront

[Title: Comparison of Flood Disaster Adaptation in Waterfront Area of Kapuas River (Pontianak and Kakap River]. Seng Hie Waterfront and Kakap waterfront are waterfront areas that are often hit by annual tidal flood disasters. This threat does not make people move but rather adapt to the disaster. These two locations have different natural features and resources. The purpose of this study is to look at the different disaster adaptation undertaken by the people in two locations that have different conditions. The method used in this research is the concurrent embedded method with a qualitative method model as the primary method and a quantitative method as a secondary method. Data collection techniques in this study are triangulation techniques (qualitative) and questionnaire techniques (quantitative). The results of the study are found that similar disasters flooding due to high tides occurred in two locations but the scale of the disaster in Kakap Waterfront was more extreme. Meanwhile, in terms of adaptation actions, in the Seng Hie Waterfront people took similar actions, while in Kakap Waterfront varied adaptation actions.

Keyword: Comparison; Building Adaptation; Behavior Adaptation; Flood; Waterfront

Cara Mengutip: Gultom, B. J. B., Jati, Dian Rahayu., \& Andi, A. (2020). Komparasi Adaptasi Bencana Banjir di Kawasan Waterfront Sungai Kapuas (Pontianak) dan Sungai Kakap. Jurnal Pengembangan Kota. Vol 8 (1): 12-22. DOI: 10.14710/jpk.8.1.12-22

\section{PENDAHULUAN}

Dalam agenda pembangunan berkelanjutan (SDGS), PBB menyatakan kota-kota pesisir (waterfront cities) di seluruh dunia terancam bencana hidrometeorologi (UCLG, 2019). Secara etimologi, bencana hidrometeorologi adalah bencana yang disebabkan perubahan iklim (fenomena meteorologi) yang mempengaruhi kondisi atmosfer (langit), kondisi hidrosfer (perairan), serta secara khusus ke kondisi alam.

ISSN 2337-7062 @ 2020

This is an open access article under the CC-BY-NC-ND license (http://creativecommons.org/licenses/by-nc-sa/4.0/). - lihat halaman depan (C) 2020

*Email bontor_jl@teknik.untan.ac.id.

Diterima 28 November 2019, disetujui 30 Juni 2020 
oseanografi (lautan) (Hermon, 2012). Bencana hidrometorologi yang dimaksud adalah bencanabencana seperti banjir, longsor, kerusakan ekosistem, degradasi lahan, puting beliung, dan kekeringan (Bobrowsky, 2013). Kegentingan untuk menyelamatkan kota-kota pesisir dikarenakan populasi di kota pesisir mencapai $50 \%$ dari total populasi manusia dan diprediksi meningkat menjadi $60 \%$ populasi manusia (United Nations, 2019).

Banjir adalah salah satu bencana hidrometeorologi yang menjadi bencana yang sering terjadi di Indonesia. Bahkan dari semua bencana yang terjadi di Indonesia, 90\% dari bencana-bencana itu tergolong bencana banjir (IDEP, 2008). Frekuensi banjir tercatat semakin naik (sering terjadi) bila dilihat dari 10 tahun yang terakhir ini (Gambar 1) (BNPB, 2020). Perubahan iklim dan naiknya emisi gas $\mathrm{CO} 2$ yang sedang terjadi menjadi faktor yang meningkatkan frekuensi banjir (Quevauviller, 2015). Banjir pada umumnya meluap dari sungai atau perairan lain dan sering mengancam kehidupan dan merusak properti (Bobrowsky, 2013). Data Badan Nasional Penanggulangan Bencana (BNPB) tahun 2016 menyatakan di Pulau Kalimantan, provinsi yang mengalami kerugian fisik, ekonomi dan jiwa terparah akibat banjir adalah Provinsi Kalimantan Barat (Rampangilei, 2016).

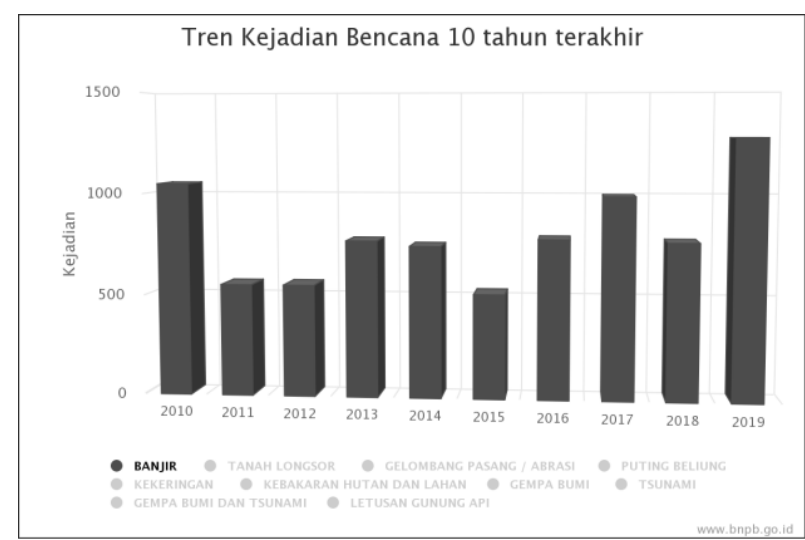

Gambar 1. Tren Bencana Banjir di Indonesia 10 Tahun Terakhir

Kawasan tepian air atau lebih dikenal waterfront merupakan lahan atau area yang terletak berbatasan dengan air seperti kota yang menghadap laut, sungai, danau atau sejenisnya (Gultom, 2012). Waterfront menjadi area yang penting untuk diteliti sebab titik awal berkembangnya sebuah kota adalah area waterfront (Niemann \& Werner, 2016). Dalam perkembangannya, waterfront memiliki 4 fase perkembangan yakni fase kemunculan (emergence of waterfront cities), fase bertumbuh (growth of waterfronts), fase pembusukan (deterioration of waterfronts), dan fase penemuan kembali (rediscovery of waterfronts) (Timur, 2013). Fasefase ini menjelaskan bahwa waterfront dari awal kemunculannya akibat kebutuhan primer akan air, yang kemudian berkembangan makin ke hulu dan menjadi area komersial, kemudian ditinggalkan karna polusi dan perubahan kebutuhan manusia, sehingga akhirnya dikembangkan kembali karena nilai historis dan nilai fisik alamnya.

Popularitas waterfront tidak luput dari ancaman bencana yang terbagi menjadi bencana yang seketika (event-based hazards) seperti badai, gempa, atau longsor, serta bencana yang bertahap (gradual hazards) waktu terjadinya seperti air pasang tinggi dan erosi (Asyah, 2020). Dalam penelitian ini, skenario bencana dibatasi hanya terfokus pada bencana banjir akibat air pasang tinggi atau jenis banjir rob. Banjir rob merupakan banjir yang terjadi akibat naiknya permukaan air laut (BNPB, 2017). Adapun istilah lain dari banjir rob ini yaitu King Tides. Kejadian ini terjadi saat matahari dan bulan dalam posisi sejajar sehingga tercipta gravitasi yang menarik air laut menjadi air pasang yang sangat tinggi (Román-Rivera \& Ellis, 2018). Di Indonesia, fenomena ini terjadi dari bulan November sampai dengan Januari. Fenomena ini dapat berlangsung selama beberapa bulan dan akan semakin parah bila disertai badai hujan.

Meskipun begitu, kawasan waterfront sampai sekarang masih menjadi tempat favorit untuk tempat tinggal. Bangunan-bangunan pemukiman tidak ditinggalkan, tidak dihindari dan tidak punah, tetapi makin berkembang. Sebaliknya, bangunan-bangunan yang ada mengalami perubahan dan melakukan perbaikan menyesuaikan dengan adanya bencana. Perubahan yang terjadi membuktikan bahwa masyarakat melakukan penyesuaian terhadap kondisi yang tidak bisa ditolak, memilih mencari solusi agar masih bisa tinggal dan bertahan di lokasi tersebut. Tindakan penyesuaian masyarakat ini dikenal dengan istilah adaptasi. 
Adaptasi adalah tindakan penyesuaian sistem alam dan sosial untuk menghadapi dampak negatif dari perubahan iklim (Riandi, 2008). Tindakan ini bertujuan untuk mengurangi kerentanan sosialekonomi dan lingkungan yang bersumber dari perubahan iklim, meningkatkan daya tahan (resilience) masyarakat dan ekosistem, sekaligus meningkatkan kesejahteraan masyarakat lokal (mengentaskan kemiskinan) (Departemen Pekerjaan Umum, 2007). Secara khusus dalam arsitektur, adaptasi dikelompokkan menjadi adaptasi perilaku dan adaptasi bangunan. Berry dalam Yusuf, Hayati, dan Faqih (2018) mengidentifikasi 3 tipe adaptasi perilaku yaitu adaptation by reaction (mengubah perilaku untuk mengurangi konflik dengan lingkungan), adaptation by adjustment (mengubah lingkungan menjadi sesuai keinginan), dan adaptation by withdrawal (membiarkan dan pindah ke lingkungan yang diinginkan). Menurut Arge dalam Carmichael dan Taheriattar (2018), terdapat 3 konsep adaptasi bangunan, yaitu generality (kemampuan bangunan untuk tidak melakukan perubahan dalam memenuhi kebutuhan pengguna), flexibility (kemampuan bangunan untuk melakukan perubahan dalam skala kecil untuk memenuhi kebutuhan pengguna) dan elasticity (kemampuan bangunan untuk diperpanjang atau dipartisi terkait dengan perubahan pengguna atau kebutuhan pemilik).

Di Kalimantan Barat, wilayah yang terzonasikan sebagai area rawan banjir rob adalah area pesisir yang dua di antaranya adalah Kawasan Waterfront Seng Hie dan Kawasan Waterfront Kakap (Gambar 2) (Haryani, 2012). Dua kawasan waterfront ini memiliki karakter yang berbeda. Seng Hie merupakan cikal bakal (embrio) Kota Pontianak sehingga memiliki peran penting dalam perkembangan kota. Kawasan Waterfront Seng Hie berbatas dengan Sungai Kapuas bercabang dan jauh dari laut adalah $20 \mathrm{~km}$.

Kakap merupakan kawasan waterfront yang merupakan bagian dari hasil pengembangan kota, yang unik karena bersentuhan dengan muara sungai dan laut. Kawasan Waterfront Kakap memiliki waterfront yang berbatas Sungai Kakap, Muara Sungai Kapuas dan laut Selat Karimata. Perbandingan kedua tempat ini selain karena termasuk area rawan banjir, juga dimaksudkan untuk melihat perbedaan perkembangan antara dua kawasan waterfront berdasarkan perbedaan geografisnya yang berbeda dari segi karakter dan skala bencananya.

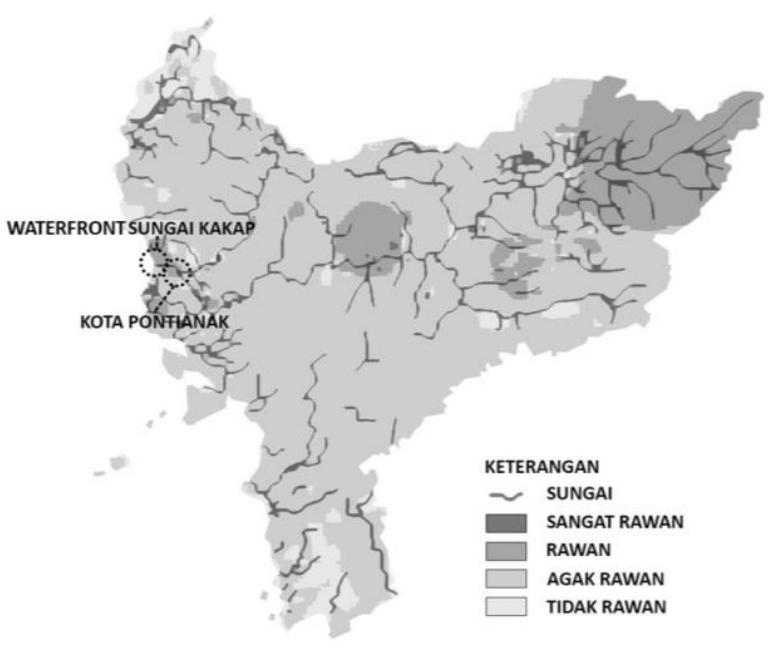

Gambar 2. Peta Zonasi Rawan Banjir di Kalimantan Barat

Kedua lokasi memiliki kesamaan berada di dekat sumber daya air berupa sungai dan laut, serta mengalami bencana banjir. Namun memiliki perbedaan dalam hal kedekatan dengan laut. Sehingga menarik untuk dilakukan komparasi lebih lanjut tentang tindakan adaptasi bencana antara 2 lokasi ini. Kedua lokasi ini diharapkan mampu mewakili daerah-daerah lain di Kalimantan Barat, dalam melihat tindakan yang dilakukan masyarakat setempat dalam beradaptasi dengan bencana. Tujuan dalam penelitian ini adalah untuk melihat perbedaan dan kesamaan dalam hal kondisi lingkungan, tindakan adaptasi dalam mengurangi risiko bencana yang dilihat dari 2 kawasan waterfront yaitu Kawasan Waterfront Seng Hie dan Kawasan Waterfront Kakap. Penelitian ini diharapkan dapat menjadi saran untuk membantu menemukan solusi pengembangan berkelanjutan bagi area waterfront dengan adaptasi-adaptasi yang menciri khaskan karakter kota atau permukiman yang ada.

\section{METODE PENELITIAN}

Penelitian ini menggunakan metode concurrent embedded dengan model metode kualitatif sebagai metode primer dan kuantitatif sebagai metode sekunder. Metode kualitatif digunakan dalam 
pengumpulan data dan analisis data. Metode kuantitatif digunakan dalam pengumpulan data dan analisis untuk memperkuat hasil temuan dari metode kualitatif. Menurut Sugiyono (2018), kombinasi dua metode ini dilakukan secara pararel (dapat berlangung bersamaan).

Lokasi objek penelitian ini adalah permukiman tepian sungai di Kota Pontianak dan Kabupaten Kuburaya. Sampel permukiman yang dijadikan objek penelitian di Kota Pontianak adalah permukiman di Kawasan Waterfront Seng Hie (Gambar 3). Sampel ini disesuaikan dengan peta rawan banjir Kota Pontianak (Kurnia, Mulki, \& Firdaus, 2019). Sampel permukiman di Kabupaten Kuburaya adalah permukiman di kawasan Waterfront Kakap yang berbatasan langsung dengan sungai dan laut (Gambar 4). Belum ada penelitian mengenai area rawan banjir di Kakap, sehingga penetapan objek didasari dengan observasi dan wawancara penduduk sekitar.

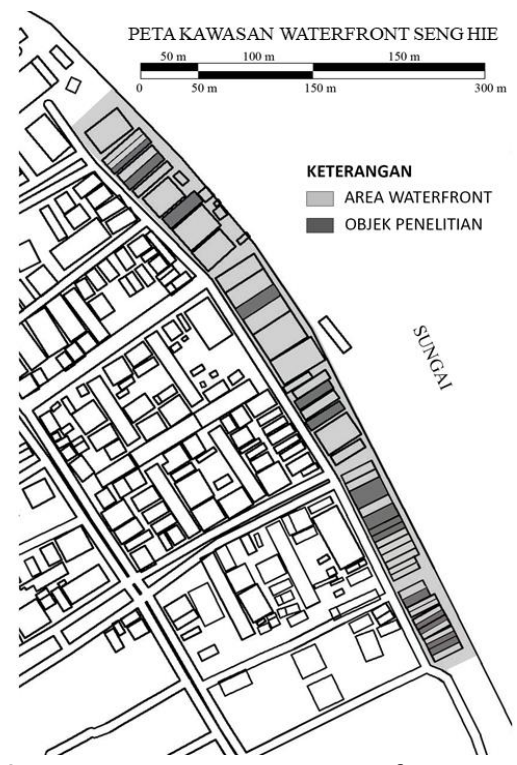

Gambar 3. Peta Kawasan Waterfront Seng Hie

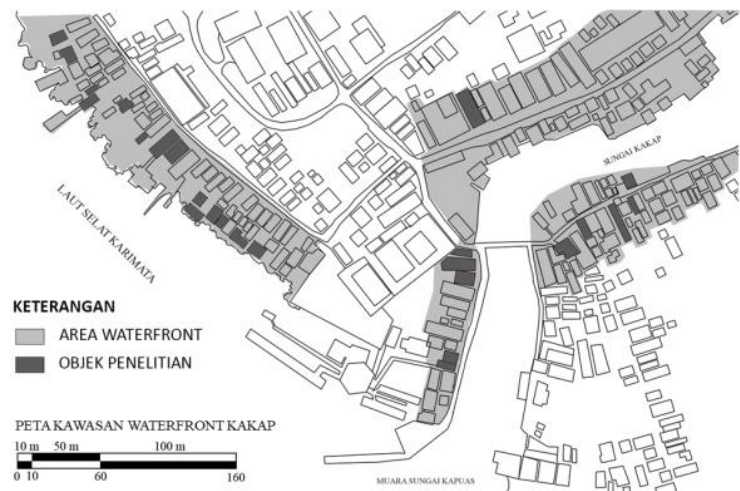

Gambar 4. Peta Kawasan Waterfront Kakap
Teknik pengumpulan data dalam penelitian ini dilakukan secara kualitatif yaitu dengan teknik triangulasi (observasi, wawancara, dan dokumentasi) ditambah dengan kuesioner. Teknik ini digunakan untuk mencari lokasi yang terkena bencana banjir. Kuesioner tersebut digunakan untuk mendata lokasi yang terkena dampak bencana, mendata skala dampak bencana yang dirasakan, dan mendata tindakan adaptasi bencana yang dilakukan masyarakat. Penelitian ini dilakukan secara bertahap dari persiapan hingga mendapatkan hasil dan simpulan (Gambar 5).

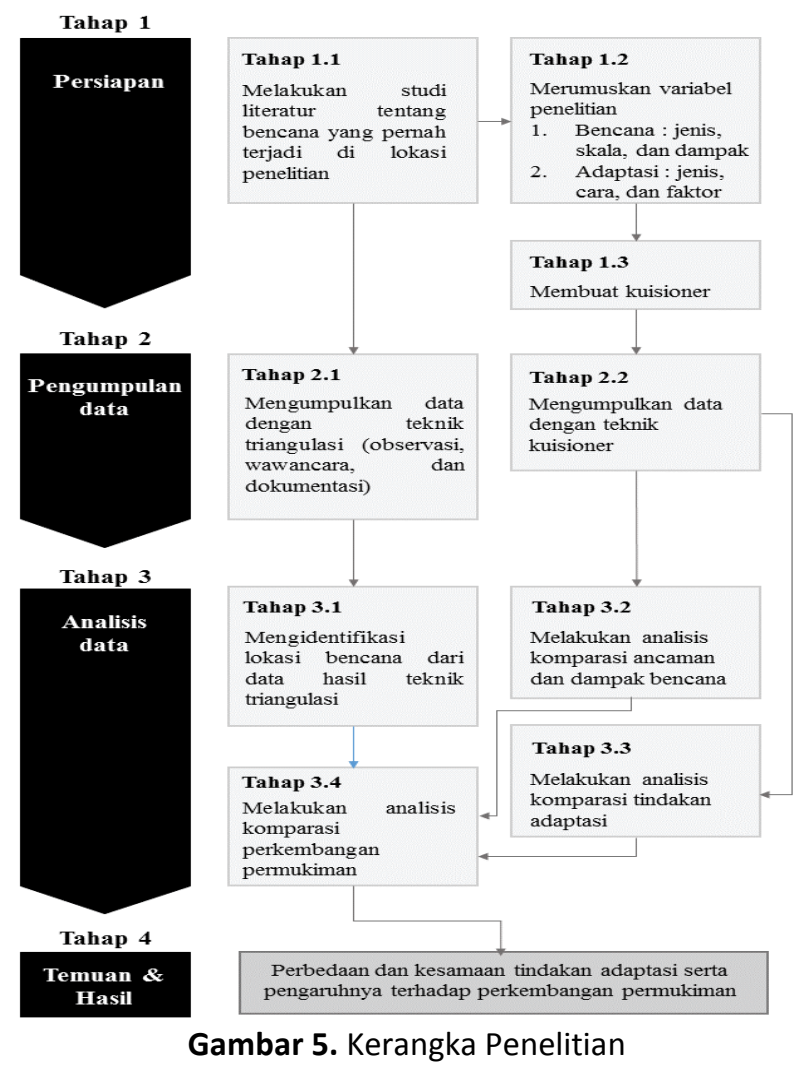

Dalam penelitian ini ada dua variabel utama yang diteliti yakni bencana dan adaptasi. Dalam mengidentifikasi bencana terdapat beberapa variabel penting untuk mengukur tingkat ancaman dan dampaknya yakni jenis, skala (waktu, ukuran, dan frekuensi), dan dampak (jenis kerusakan dan tingkat kerusakan) (IDEP, 2007). Identifikasi adaptasi dilakukan dengan mengetahui kegiatan yang dilakukan saat bencana dan cara menanggapi bencana. Informasi tersebut kemudian dianalisis untuk dikelompokkan ke dalam klasifikasi adaptasi bangunan dan adaptasi perilaku sesuai dengan teori Berry (1980) dan Arge (2005). Variabel-variabel ini kemudian dirumuskan ke 
dalam instrumen penelitian yang berbentuk kuesioner (Tabel 1).

Tabel 1. Variabel Identifikasi Pertanyaan Kuesioner

\begin{tabular}{|c|c|c|}
\hline $\begin{array}{c}\text { Variabel } \\
\text { Identifikasi }\end{array}$ & & Pertanyaan Kuesioner \\
\hline \multirow{8}{*}{$\begin{array}{c}\text { Bencana dan } \\
\text { Dampak Bencana }\end{array}$} & 1 & Lama huni \\
\hline & 2 & $\begin{array}{l}\text { Alasan memilih lokasi } \\
\text { tempat tinggal }\end{array}$ \\
\hline & 3 & Bencana pada musim hujan \\
\hline & 4 & $\begin{array}{l}\text { Frekuensi bencana dalam } \\
\text { setahun }\end{array}$ \\
\hline & 5 & Ketinggian air saat banjir \\
\hline & 6 & Lama banjir terjadi \\
\hline & 7 & Dampak negatif dari banjir \\
\hline & 8 & $\begin{array}{l}\text { Properti bangunan yang } \\
\text { rusak }\end{array}$ \\
\hline \multirow{9}{*}{$\begin{array}{l}\text { Tindakan } \\
\text { Adaptasi } \\
\text { Bencana }\end{array}$} & 9 & Frekuensi renovasi rumah \\
\hline & 10 & Bagian yang direnovasi \\
\hline & 11 & Alasan renovasi \\
\hline & 12 & Jenis bahan rumah \\
\hline & 13 & menghadapi \\
\hline & 14 & $\begin{array}{l}\text { Alasan anda tetap tinggal di } \\
\text { lokasi saat ini }\end{array}$ \\
\hline & 15 & $\begin{array}{l}\text { Tempat yang dituju saat } \\
\text { banjir }\end{array}$ \\
\hline & 16 & $\begin{array}{l}\text { Tindakan tanggap darurat } \\
\text { saat banjir }\end{array}$ \\
\hline & 17 & $\begin{array}{l}\text { Alasan tetap tinggal } \\
\text { meskipun terkena bencana }\end{array}$ \\
\hline
\end{tabular}

Untuk melihat perbedaan tindakan adaptasi antara dua lokasi penelitian, dilakukan analisis komparasi data dari kuesioner dan hasil observasi serta wawancara. Komparasi dibagi menjadi 3 bagian. Komparasi pertama untuk melihat tingkat ancaman bencana dan dampak bencana yang paling besar antara 2 lokasi ini. Komparasi bagian kedua adalah untuk melihat bagaimana tindakan adaptasi dilakukan masyarakat menghadapi bencana antara 2 lokasi penelitian. Komparasi bagian ketiga adalah untuk membandingkan tindakan adaptasi bangunan dari elemen-elemen bangunannya.

\section{HASIL DAN PEMBAHASAN}

\subsection{Identifikasi Lokasi Bencana}

Berdasarkan Saragih (2014) dalam beritasatu.com, Kota Pontianak mengalami banjir pada tahun 2014. Banjir ini mengakibatkan beberapa ruas jalan tertutupi air sehingga mengganggu aktivitas masyarakat. Menurut media ini, banjir disebabkan saluran drainase yang tersumbat dan intensitas air hujan yang meningkat sehingga tidak mampu ditampung oleh drainase (Gambar 6).

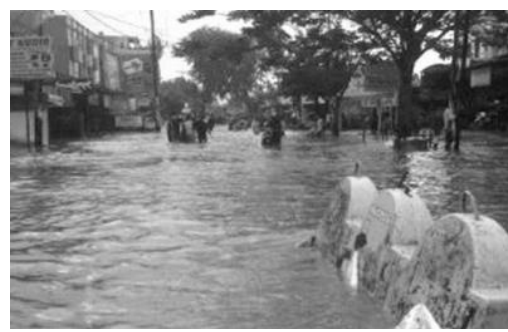

Gambar 6. Kondisi Banjir di Kota Pontianak tahun 2014

Berdasarkan hasil temuan Kurniawan, Habibie, dan Permana (2012) dalam penelitiannya tentang daerah rawan gelombang tinggi di Indonesia, ditemukan daerah yang rawan gelombang tinggi. Dari paparan tersebut disebutkan bahwa gelombang tinggi terjadi terjadi gelombang tinggi di Selat Karimata dan Laut China Selatan. Sehingga daerah yang mengalami mengalami dampak gelombang tinggi adalah daerah di Kawasan Waterfront Kakap, Kabupaten Kuburaya (Gambar 7). Hal ini terjadi pada bulan Desember sampai bulai Januari.

Lokasi bencana di Kabupaten Kuburaya diidentifikasi berdasarkan studi dokumen dan analisis dari peta. Hasil identifikasi menemukan bahwa daerah pesisir Kabupaten Kuburaya berpotensi bencana khusus nya Kawasan Waterfront Kakap. Bencana yang terjadi di Kawasan Waterfront Kakap adalah bencana gelombang tinggi dan terjadi selama bulan Desember sampai bulan Januari.

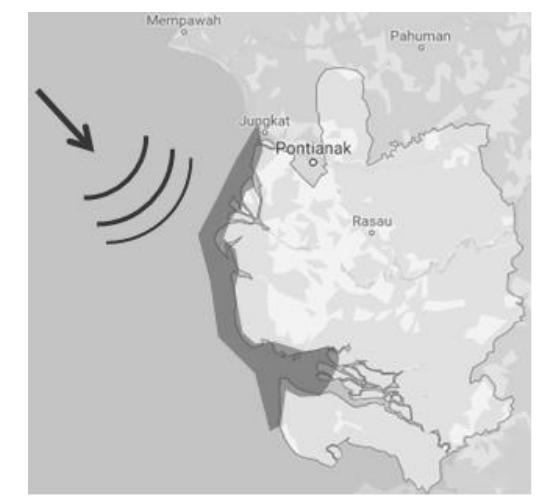

Gambar 7. Peta Rawan Gelombang Tinggi di Kabupaten Kuburaya 


\subsection{Komparasi Tingkat Ancaman bencana dan dampak bencana}

Berdasarkan Tabel 2 didapatkan beberapa hasil analisis data kuesioner yang menunjukkan tingkat ancaman bencana dan dampak bencana yang paling besar antara 2 lokasi penelitian. Masyarakat Kawasan Waterfront Kakap dan Kawasan Waterfront Seng Hie menghadapi banjir akibat cuaca yang terjadi setiap bulan Desember. Oleh karena lokasi Kawasan Waterfront Kakap dekat dengan laut, sehingga banjir disertai dengan angin kencang. Dari segi kerusakan, masyarakat Kawasan Waterfront Kakap menderita kerusakan bangunan lebih banyak dibandingkan dengan masyarakat Kawasan Waterfront Seng Hie. Dapat disimpulkan bahwa ancaman bencana di Kawasan Waterfront Kakap lebih besar dibandingkan dengan Kawasan Waterfront Seng Hie dan dampak kerusakan bencana di Kawasan Waterfront Kakap lebih besar dibandingkan dengan Kawasan Waterfront Seng Hie.

Tabel 2. Komparasi Tingkat Ancaman dan Dampak Bencana

\begin{tabular}{|c|c|c|c|}
\hline $\begin{array}{l}\text { Variabel } \\
\text { Komparasi }\end{array}$ & $\begin{array}{c}\text { Kota Pontianak } \\
\text { (Kawasan } \\
\text { Waterfront Seng Hie) }\end{array}$ & $\begin{array}{c}\text { Kab. Kuburaya } \\
\text { (Kawasan } \\
\text { Waterfront Kakap) }\end{array}$ & Analisis \\
\hline Lama Tinggal & $\begin{array}{l}13 \% 5-10 \text { tahun } \\
53 \% 10-15 \text { tahun } \\
33 \%>20 \text { tahun }\end{array}$ & $\begin{array}{l}4 \% \text { 0-3 tahun } \\
8 \% \text { 3-5 tahun } \\
8 \% \text { 5-10 tahun } \\
28 \% 10-15 \text { tahun } \\
52 \%>20 \text { tahun }\end{array}$ & $\begin{array}{l}\text { Masyarakat di Kawasan Waterfront } \\
\text { Seng Hie sebagian besar menetap } \\
\text { rumah nya lebih singkat (10 - } 15 \\
\text { tahun) dibanding dengan masyarakat } \\
\text { Kawasan Waterfront Kakap (kurang } \\
\text { dari } 20 \text { tahun) }\end{array}$ \\
\hline $\begin{array}{l}\text { Alasan huni di } \\
\text { lokasi }\end{array}$ & $\begin{array}{l}93 \% \text { dekat pasar } \\
6 \% \text { sudah turun- } \\
\text { temurun }\end{array}$ & $\begin{array}{l}40 \% \text { dekat tempat } \\
\quad \text { kerja } \\
32 \% \text { dekat pasar } \\
4 \% \text { jauh dari kota } \\
36 \% \text { sudah turun- } \\
\quad \text { temurun }\end{array}$ & $\begin{array}{l}\text { Alasan huni masyarakat Kawasan } \\
\text { Waterfront Seng Hie karena dekat } \\
\text { dengan pasar sedangkan masyarakat } \\
\text { Kawasan Waterfront Kakap } \\
\text { bermacam-macam (dekat tempat } \\
\text { kerja, dekat pasar dan karena sudah } \\
\text { turun temurun }\end{array}$ \\
\hline $\begin{array}{l}\text { Bencana yang } \\
\text { terjadi }\end{array}$ & $\begin{array}{l}20 \% \text { banjir } \\
80 \% \text { pasang air }\end{array}$ & $\begin{array}{l}32 \% \text { banjir } \\
80 \% \text { pasang air }\end{array}$ & $\begin{array}{l}\text { Bencana yang dialami di } 2 \text { lokasi ini } \\
\text { kurang lebih sama yaitu bencana } \\
\text { banjir akibat air pasang tinggi pada } \\
\text { bulan Desember }\end{array}$ \\
\hline $\begin{array}{l}\text { Frekuensi } \\
\text { bencana dalam } \\
\text { setahun }\end{array}$ & $\begin{array}{l}86 \% 1 \text { kali } \\
13 \% 2 \text { kali }\end{array}$ & $\begin{array}{l}88 \% 1 \text { kali } \\
12 \% 2 \text { kali }\end{array}$ & $\begin{array}{l}\text { Frekuensi bencana yang dialami di } 2 \\
\text { lokasi ini kurang lebih sama yaitu } 1 \\
\text { kali setahun. }\end{array}$ \\
\hline $\begin{array}{l}\text { Ketinggian air } \\
\text { genangan }\end{array}$ & $100 \% 0-1$ meter & $\begin{array}{l}84 \% \text { 0-1 meter } \\
16 \% 1-2 \text { meter }\end{array}$ & $\begin{array}{l}\text { Ketinggian genangan air di } 2 \text { lokasi } \\
\text { kurang lebih sama yaitu tidak lebih } \\
\text { dari } 1 \text { meter atau } 5 \mathrm{~cm} \text { sampai } 20 \mathrm{~cm} \\
\text { dari lantai rumah }\end{array}$ \\
\hline Lama genangan & $\begin{array}{l}60 \%<1 \text { hari } \\
40 \%<2 \text { jam }\end{array}$ & $\begin{array}{l}84 \%<1 \text { hari } \\
16 \%<2 \text { jam }\end{array}$ & $\begin{array}{l}\text { Lama air menggenang di } 2 \text { lokasi ini } \\
\text { kurang lebih sama yaitu sekitar atau } \\
\text { kurang dari } 2 \text { jam. }\end{array}$ \\
\hline Dampak negatif & $\begin{array}{l}10 \% \text { kerusakan } \\
\text { bangunan } \\
43 \% \text { kerusakan } \\
\text { perabot rumah } \\
\text { 40\% kerusakan } \\
\text { lingkungan } \\
13 \% \text { sulit akses }\end{array}$ & $\begin{array}{l}96 \% \text { kerusakan } \\
\text { bangunan } \\
24 \% \text { kerusakan } \\
\text { lingkungan }\end{array}$ & $\begin{array}{l}\text { Dampak negatif yang dirasakan oleh } \\
\text { masyarakat Kawasan Waterfront Seng } \\
\text { Hie adalah kerusakan perabot, dan } \\
\text { kerusakan lingkungan sedangkan } \\
\text { masyarakat di Kawasan Waterfront } \\
\text { Kakap merasakan kerusakan } \\
\text { bangunan. }\end{array}$ \\
\hline $\begin{array}{l}\text { Properti yang } \\
\text { rusak }\end{array}$ & $\begin{array}{l}\text { 7\% lantai } \\
7 \% \text { dinding }\end{array}$ & $\begin{array}{l}36 \% \text { lantai } \\
28 \% \text { dinding } \\
16 \% \text { tiang }\end{array}$ & $\begin{array}{l}\text { Kerusakan properti yang dirasakan } \\
\text { oleh masyarakat Kawasan Waterfront } \\
\text { Seng Hie adalah lantai dan dinding, } \\
\text { sedangkan kerusakan properti yang }\end{array}$ \\
\hline
\end{tabular}




\begin{tabular}{|c|c|c|c|}
\hline $\begin{array}{l}\text { Variabel } \\
\text { Komparasi }\end{array}$ & $\begin{array}{c}\text { Kota Pontianak } \\
\text { (Kawasan } \\
\text { Waterfront Seng Hie) }\end{array}$ & $\begin{array}{c}\text { Kab. Kuburaya } \\
\text { (Kawasan } \\
\text { Waterfront Kakap) }\end{array}$ & Analisis \\
\hline & & & $\begin{array}{l}\text { masyarakat di Kawasan Waterfront } \\
\text { Kakap adalah lantai, dinding, dan } \\
\text { tiang. Sehingga dapat disimpulkan } \\
\text { dari persentase yang tertinggi bahwa } \\
\text { banjir merusak lantai rumah. }\end{array}$ \\
\hline
\end{tabular}

\subsection{Komparasi Tindakan Adaptasi}

Berdasarkan Tabel 3 didapatkan beberapa hasil analisis data kuesioner yang menunjukkan tindakan adaptasi masyarakat antara 2 lokasi penelitian. Masyarakat Kawasan Waterfront Kakap lebih sering melakukan renovasi pada rumahnya. Bagian yang paling sering direnovasi di 2 lokasi ini adalah bagian lantai. Khusus untuk masyarakat Kawasan Waterfront Kakap, mereka melakukan renovasi pada tiang rumah. Alasan masyarakat melakukan renovasi di 2 lokasi ini adalah untuk estetika dan untuk mencegah air masuk.
Masyarakat di 2 lokasi ini mengaku bahwa mereka melakukan merencanakan renovasi untuk memperindah rumah mereka, dan sambilan untuk mencegah air banjir masuk. Rumah di Kawasan Waterfront Kakap pada umumnya dari kayu dan direnovasi menjadi beton, tetapi masih banyak yang dari kayu. Sedangkan rumah di Kawasan Waterfront Seng Hie, hampir semuanya sudah direnovasi menjadi berbahan beton. Alhasil, masih ada masyarakat di Kawasan Waterfront Kakap yang mengungsi saat banjir dan di Kawasan Waterfront Seng Hie tidak ada masyarakat yang mengungsi.

Tabel 3. Komparasi Tingkat Adaptasi Bencana dari Data Kuisioner

\begin{tabular}{|c|c|c|c|}
\hline $\begin{array}{l}\text { Variabel } \\
\text { Komparasi }\end{array}$ & $\begin{array}{l}\text { Kota Pontianak } \\
\text { (Kawasan } \\
\text { Waterfront Seng } \\
\text { Hie) }\end{array}$ & $\begin{array}{l}\text { Kab. Kuburaya } \\
\text { (Kawasan } \\
\text { Waterfront } \\
\text { Kakap) }\end{array}$ & Analisis \\
\hline $\begin{array}{l}\text { Frekuensi } \\
\text { renovasi }\end{array}$ & $\begin{array}{l}26 \% \text { belum pernah } \\
46 \% 1 \text { kali } \\
26 \% 2 \text { kali }\end{array}$ & $\begin{array}{l}12 \% \text { belum pernah } \\
32 \% 1 \text { kali } \\
32 \% 2 \text { kali } \\
28 \% 3 \text { kali }\end{array}$ & $\begin{array}{l}\text { Sebagian besar Frekuensi renovasi di } \\
\text { Kawasan Waterfront Seng Hie adalah } 1 \text { kali, } \\
\text { sedangkan di Kawasan Waterfront Kakap } \\
\text { bermacam-macam ( } 1 \text { kali, } 2 \text { kali, dan } 3 \text { kali). }\end{array}$ \\
\hline Renovasi & $\begin{array}{l}\text { 53\% Lantai } \\
\text { 20\% Dinding }\end{array}$ & $\begin{array}{l}80 \% \text { Lantai } \\
40 \% \text { Dinding } \\
28 \% \text { Tiang }\end{array}$ & $\begin{array}{l}\text { Pada } 2 \text { lokasi ini bagian yang paling banyak } \\
\text { direnovasi adalah lantai. Adapun sebagian } \\
\text { kecil merenovasi dinding. Hanya Di Kawasan } \\
\text { Waterfront Kakap yang merenovasi tiang. }\end{array}$ \\
\hline Alasan renovasi & $\begin{array}{l}33 \% \text { estetika } \& \\
\text { kenyamanan } \\
13 \% \text { konstruksi } \\
46 \% \text { cegah air } \\
\quad \text { masuk }\end{array}$ & $\begin{array}{l}56 \% \text { estetika } \& \\
\text { kenyamanan } \\
16 \% \text { konstruksi } \\
48 \% \text { cegah air } \\
\text { masuk }\end{array}$ & $\begin{array}{l}\text { Sebagian besar masyarakat di } 2 \text { lokasi yaitu } \\
\text { di Kawasan Waterfront Seng Hie dan } \\
\text { Kawasan Waterfront Kakap merenovasi } \\
\text { rumah dengan alasan yang sama untuk } \\
\text { mencegah air masuk dan untuk estetika. }\end{array}$ \\
\hline $\begin{array}{l}\text { Jenis Bahan } \\
\text { Rumah }\end{array}$ & $\begin{array}{l}80 \% \text { beton } \\
20 \% \text { kayu } \& \text { beton }\end{array}$ & $\begin{array}{l}28 \% \text { kayu } \\
72 \% \text { kayu \& beton }\end{array}$ & $\begin{array}{l}\text { Rumah di Kawasan Waterfront Seng Hie } \\
\text { mayoritas bermaterial beton dan sebagian } \\
\text { kecil bermaterial kayu dan beton. } \\
\text { Sedangkan di Kawasan Waterfront Kakap, } \\
\text { rumah berbahan kayu dan beton dan } \\
\text { sebagian kecil dari kayu. }\end{array}$ \\
\hline $\begin{array}{l}\text { Tindakan } \\
\text { menghadapi } \\
\text { banjir }\end{array}$ & $\begin{array}{r}\text { 100\% menetap } \\
\text { ditempat }\end{array}$ & $\begin{array}{l}68 \% \text { menetap di } \\
\text { tempat } \\
32 \% \text { pindah atau } \\
\text { mengungsi }\end{array}$ & $\begin{array}{l}\text { Tindakan semua masyarakat di Kawasan } \\
\text { Waterfront Seng Hie adalah menetap di } \\
\text { rumah, sedangkan di Kakap sebagian besar } \\
\text { menetap dan sebagian kecil yang } \\
\text { mengungsi. }\end{array}$ \\
\hline Alasan menetap & $27 \%$ dekat tempat & $28 \%$ dekat tempat & Alasan masyarakat di 2 lokasi ini tetap di \\
\hline
\end{tabular}




\begin{tabular}{|c|c|c|c|}
\hline $\begin{array}{l}\text { Variabel } \\
\text { Komparasi }\end{array}$ & $\begin{array}{l}\text { Kota Pontianak } \\
\text { (Kawasan } \\
\text { Waterfront Seng } \\
\text { Hie) }\end{array}$ & $\begin{array}{l}\text { Kab. Kuburaya } \\
\text { (Kawasan } \\
\text { Waterfront } \\
\text { Kakap) }\end{array}$ & Analisis \\
\hline $\begin{array}{c}\text { di tempat } \\
\text { meskipun banjir }\end{array}$ & $\begin{array}{l}\text { kerja } \\
\text { 73\% banjir tidak } \\
\text { terlalu parah }\end{array}$ & $\begin{array}{l}\text { kerja } \\
\text { 48\% banjir tidak } \\
\text { terlalu parah }\end{array}$ & $\begin{array}{l}\text { tempat saat banjir karena alasan pekerjaan } \\
\text { dan mereka merasa banjir tidak terlalu } \\
\text { parah. }\end{array}$ \\
\hline $\begin{array}{l}\text { Tempat yang } \\
\text { dituju saat banjir }\end{array}$ & $\begin{array}{l}100 \% \text { tetap di } \\
\text { rumah }\end{array}$ & $\begin{array}{l}24 \% \text { posko bencana } \\
32 \% \text { bangunan } \\
\text { umum sekitar }\end{array}$ & $\begin{array}{l}\text { Tempat yang dituju masyarakat Kawasan } \\
\text { Waterfront Kakap saat banjir adalah posko } \\
\text { bencana dan bangunan umum sekitar, } \\
\text { sedangkan masyarakat Kawasan Waterfront } \\
\text { Seng Hie memilih untuk tetap di rumah. }\end{array}$ \\
\hline $\begin{array}{l}\text { Tindakan tanggap } \\
\text { darurat }\end{array}$ & $\begin{array}{l}\text { 27\% membuat } \\
\text { pembatas air } \\
73 \% \text { tidak } \\
\text { melakukan } \\
\text { apa }\end{array}$ & $\begin{array}{l}84 \% \text { meninggikan } \\
\text { bangunan } \\
24 \% \text { membuat } \\
\text { pembatas air }\end{array}$ & $\begin{array}{l}\text { Tindakan tanggap darurat masyarakat } \\
\text { Kawasan Waterfront Seng Hie adalah tidak } \\
\text { melakukan apa-apa, sedangkan masyarakat } \\
\text { Kawasan Waterfront Kakap membuat } \\
\text { pembatas agar air tidak masuk. }\end{array}$ \\
\hline $\begin{array}{l}\text { Alasan tinggal } \\
\text { dilokasi }\end{array}$ & $\begin{array}{l}64 \% \text { dekat tempat } \\
\text { kerja } \\
12 \% \text { dekat keluarga } \\
24 \% \text { sudah lama } \\
\text { bermukim }\end{array}$ & $\begin{array}{l}44 \% \text { dekat tempat } \\
\text { kerja } \\
44 \% \text { dekat keluarga } \\
36 \% \text { sudah lama } \\
\text { bermukim }\end{array}$ & $\begin{array}{l}\text { Alasan masyarakat di } 2 \text { lokasi ini tetap } \\
\text { tinggal di lokasi saat ini adalah sama yaitu } \\
\text { karena dekat tempat kerja, dekat keluarga, } \\
\text { dan sudah lama bermukim }\end{array}$ \\
\hline
\end{tabular}

Berdasarkan Tabel 4 didapatkan hasil analisis observasi dan wawancara yang menunjukkan perbedaan golongan tindakan adaptasi yang dilakukan oleh masyarakat di masing-masing lokasi penelitian. Golongan tindakan adaptasi diklasifikasikan menggunakan teori adaptasi bangunan dan adaptasi perilaku seperti pada tinjauan pustaka. Tindakan adaptasi di Kawasan Waterfront Seng Hie memiliki kesamaan dengan adaptasi Kelompok 2 di Kawasan Waterfront Kakap. Kesamaan juga terlihat dari jenis bangunannya yang merupakan bangunan bergaya ruko. Tiga kelompok lainnya di Kawasan Waterfront Kakap memiliki tindakan adaptasi yang unik. Kelompok 1 tidak melakukan adaptasi bangunan sama sekali dan masyarakatnya mengungsi ketika bencana terjadi. Kelompok 3 memperbaiki bagian bangunan yang rusak kembali pada seperti keadaan semula. Kelompok 4 mengubah bangunan sehingga dapat dimodifikasi sesuai kebutuhan saat banjir dan saat tidak banjir.

Tabel 4. Komparasi Tindakan Adaptasi Bangunan dan Adaptasi Perilaku

\begin{tabular}{cccl}
\hline Variabel Komparasi & $\begin{array}{c}\text { Adaptasi } \\
\text { Bangunan }\end{array}$ & $\begin{array}{c}\text { Adaptasi } \\
\text { Perilaku }\end{array}$ & \multicolumn{1}{c}{ Analisis } \\
\hline $\begin{array}{c}\text { Kawasan Waterfront Seng } \\
\text { Hie }\end{array}$ & Flexibility & Adjustment & $\begin{array}{l}\text { Masyarakat Kawasan Waterfront Seng Hie } \\
\text { melakukan perbaikan agar bangunan nya } \\
\text { tidak tergenang air banjir lagi. Rumah } \\
\text { mereka dapat diubah dalam skala kecil } \\
\text { seperti lantai yang dapat terus diubah } \\
\text { bertambah tinggi. }\end{array}$ \\
& & \\
\end{tabular}




\begin{tabular}{|c|c|c|c|}
\hline Variabel Komparasi & $\begin{array}{l}\text { Adaptasi } \\
\text { Bangunan }\end{array}$ & $\begin{array}{l}\text { Adaptasi } \\
\text { Perilaku }\end{array}$ & Analisis \\
\hline $\begin{array}{l}\text { Kawasan Waterfront Kakap } \\
\text { (Kelompok 1) }\end{array}$ & Tidak Ada & Withdrawal & $\begin{array}{l}\text { Masyarakat Kawasan Waterfront Kakap } \\
\text { kelompok } 1 \text { menarik diri dari rumahnya } \\
\text { ketika banjir datang, dan bangunan mereka } \\
\text { sama sekali tidak beradaptasi terhadap } \\
\text { bencana. }\end{array}$ \\
\hline $\begin{array}{c}\text { Kawasan Waterfront Kakap } \\
\text { (Kelompok 2) }\end{array}$ & Flexibility & Adjustment & $\begin{array}{l}\text { Masyarakat Kawasan Waterfront Kakap } \\
\text { kelompok } 2 \text { memiliki adaptasi bangunan } \\
\text { dan adaptasi perilaku yang sejenis dengan } \\
\text { masyarakat Seng Hie. }\end{array}$ \\
\hline $\begin{array}{l}\text { Kawasan Waterfront Kakap } \\
\text { (Kelompok 3) }\end{array}$ & Generality & Reaction & $\begin{array}{l}\text { Masyarakat Kawasan Waterfront Kakap } \\
\text { kelompok } 3 \text { bertindak untuk mengurangi } \\
\text { konflik dengan kondisi lingkungan saat } \\
\text { banjir. Mereka melakukan perbaiki tanpa } \\
\text { mengubah kondisi awal bangunan. }\end{array}$ \\
\hline $\begin{array}{l}\begin{array}{c}\text { Kawasan Waterfront Kakap } \\
\text { (Kelompok 4) }\end{array} \\
\text { |Hill| }\end{array}$ & Elasticity & Adjustment & $\begin{array}{l}\text { Masyarakat Kawasan Waterfront Kakap } \\
\text { kelompok } 4 \text { melakukan perbaikan pada } \\
\text { bangunan sehingga bangunan menjadi } \\
\text { partisi yang elastik (dapat dilepas pasang) } \\
\text { sesuai kebutuhan. }\end{array}$ \\
\hline
\end{tabular}

\section{KESIMPULAN}

Berdasarkan komparasi hasil kuesioner, wawancara, dan observasi dari 2 lokasi penelitian, didapatkan kesimpulan bahwa dari segi kondisi lingkungan, bencana di Kawasan Waterfront Kakap dan Kawasan Senghie adalah bencana yang sejenis yaitu banjir akibat air pasang tinggi tetapi skala bencana di Kawasan Waterfront Kakap lebih ekstrim (Tabel 5). Hal ini diakibatkan oleh jenis waterfront yang berbeda. Waterfront di Kawasan
Waterfront Kakap tergolong waterfront pada tepian badan air yang besar seperti laut, sedangkan di Kawasan Waterfront Seng Hie (Pontianak) tergolong waterfront pada tepian sungai (Timur, 2013). Kondisi waterfront laut memang lebih ganas karena disertai dengan badai angin munson, sedangkan pada sungai yang jarak nya $20 \mathrm{~km}$ dari laut cenderung lebih tenang (Kurniawan dkk., 2012).

Dari segi tindakan adaptasi, di Kawasan Waterfront Seng Hie masyarakat melakukan tindakan yang 
sejenis. Hal ini menjelaskan perilaku masyarakat di Seng Hie secara homogen memiliki kemampuan untuk merubah lingkungan sesuai dengan kebutuhannya (adaptation by adjustment) (Berry, 1980) dan adaptasi bangunan yang dilakukan bersifat flexible dimana ketinggian lantai dapat diubah (Arge, 2005). Sedangkan di Kawasan Waterfront Kakap terdapat golongan masyarakat yang tidak dapat melakukan perubahan lingkungan dan terpaksa untuk mengungsi sementara (adaptation by withdrawal) (Berry, 1980) karena secara ekonomi tidak mampu mengubah bangunan dan bangunannya pun tidak menjadi tempat yang aman saat terjadi bencana. Ada juga yang masyarakat yang bertahan dalam bangunan (generality) dan bereaksi menyelamatkan perabot selama banjir terjadi (adaptation by reaction) (Berry, 1980). Di Kawasan Waterfront Kakap Juga memiliki kelompok masyarakat yang beradaptasi seperti masyarakat di Kawasan Waterfront Seng Hie.

Tabel 5. Kesimpulan Komparasi Bencana dan Adaptasi Antara Kota Pontianak dan Kabupaten Kuburaya

\begin{tabular}{|c|c|c|c|}
\hline Keterangan & Variabel Komparasi & $\begin{array}{l}\text { Kota Pontianak } \\
\text { (Kawasan } \\
\text { Waterfront Seng Hie) }\end{array}$ & $\begin{array}{l}\text { Kab. Kuburaya (Kawasan Waterfront } \\
\text { Kakap) }\end{array}$ \\
\hline \multirow{7}{*}{ Perbedaan } & Lama Huni & $\begin{array}{l}\text { Kurang lama }(10-15 \\
\text { tahun) }\end{array}$ & Lebih lama (15 - 20 tahun) \\
\hline & Skala Bencana & $\begin{array}{l}\text { Kurang ekstrim (jauh } \\
\text { dari laut) }\end{array}$ & $\begin{array}{l}\text { Lebih ekstrim (disertai angin kencang } \\
\text { dari laut) }\end{array}$ \\
\hline & Dampak Bencana & Sedikit kerusakan & Banyak kerusakan \\
\hline & Frekuensi Renovasi & Kurang banyak & Lebih banyak \\
\hline & Bahan Rumah & $\begin{array}{l}\text { Lebih berdaya tahan } \\
\text { tinggi (beton dan } \\
\text { campuran beton } \\
\text { kayu) }\end{array}$ & $\begin{array}{l}\text { Kurang berdaya tahun tinggi (kayu dan } \\
\text { campuran beton kayu) }\end{array}$ \\
\hline & $\begin{array}{l}\text { Respon terhadap } \\
\text { Bencana }\end{array}$ & $\begin{array}{ll}\text { Semua } & \text { tetap } \\
\text { ditempat } & \\
\end{array}$ & Sebagian mengungsi \\
\hline & $\begin{array}{l}\text { Tindakan Adaptasi } \\
\text { bangunan dan } \\
\text { adaptasi Perilaku } \\
\text { yang berbeda }\end{array}$ & $\begin{array}{l}\text { Kawasan Waterfront } \\
\text { Seng Hie (Flexibility } \\
\text { dan Adjustment) }\end{array}$ & $\begin{array}{l}\text { Kawasan Waterfront Kakap } \\
\text { Kelompok } 1 \text { (Tidak ada dan } \\
\text { Withdrawal), } \\
\text { Kelompok } 3 \text { (Generality dan Reaction), } \\
\text { dan } \\
\text { Kelompok } 4 \text { (Elasticity dan Adjustment) }\end{array}$ \\
\hline
\end{tabular}

\section{DAFTAR PUSTAKA}

Asyah, A. N. (2020). Waterfront City dan Upaya Penanggulangan Bencana. Retrieved 5 Juli, 2020, from https://www.handalselaras.com/waterfron t-city-dan-upaya-penanggulanganbencana/

BNPB. (2017). Definisi dan Jenis Bencana. Jakarta: Badan Nasional Penanggulangan Bencana Retrieved from https://bnpb.go.id/potensibencana.

BNPB. (2020). Data Informasi Bencana Indonesia (DIBI). Jakarta: Badan Nasional Penanggulangan Bencana Retrieved from https://bnpb.cloud/dibi/.
Bobrowsky, P. T. (2013). Encyclopedia of natural hazards: includes case studies. Dordrecht: Springer Netherlands.

Carmichael, D. G., \& Taheriattar, R. (2018). Valuing Deliberate Built-in Flexibility in HousesExampled. International Journal of Strategic Property Management, 22(6), 479-488. Doi: 10.3846/ijspm.2018.6273

Departemen Pekerjaan Umum. (2007). Rencana Aksi Mitigasi dan Adaptasi Terhadap Perubahan Iklim Bidang Pekerjaan Umum. Jakarta: Departemen Pekerjaan Umum.

Gultom, B. J. (2012). Identifikasi Jalur Pejalan Kaki di Kawasan Waterfront, Seng Hie, Pontianak. DIMENSI (Journal of Architecture and Built Environment), 39(2), 77-82. Doi: 10.9744/dimensi.39.2.77-82 
Haryani, N. S. (2012). Penentuan Zona Potensi Tingkat Kerawanan Banjir Menggunakan Data Penginderaan Jauh dan SIG di Kalimantan Barat. Tataloka, 14(1), 26-36. Doi: 10.14710/tataloka.14.1.26-36

Hermon, D. (2012). Mitigasi Bencana Hidrometeorologi: Banjir, Lonsor, Ekologi, Degradasi Lahan, Puting Beliung, Kekeringan. Padang (ID): UNP Press.

IDEP. (2007). Panduan Umum Penanggulangan Bencana Berbasis Masyarakat. Bali: Yayasan IDEP.

IDEP. (2008). Pendidikan Siaga Bencana. Bandung: ITB.

Kurnia, M. I., Mulki, G. Z., \& Firdaus, H. (2019). Pemetaan Rawan Banjir di Kecamatan Pontianak Selatan dan Pontianak Tenggara Berbasis Sistem Informasi Geografis (SIG). Jurnal Mahasiswa Teknik Sipil Universitas Tanjungpura, 6(2), 1-7.

Kurniawan, R., Habibie, M. N., \& Permana, D. S. (2012). Kajian Daerah Rawan Gelombang Tinggi di Perairan Indonesia. Jurnal Meteorologi dan Geofisika, 13(3), 201-212. Doi: 10.31172/jmg.v13i3.135

Niemann, B., \& Werner, T. (2016). Strategies for the Sustainable Urban Waterfront Vol. 204. WIT Transactions on Ecology and the Environment (pp. 431-439).

Quevauviller, P. (2015). Hydrometeorological Hazards: Interfacing Science and Policy. Amerika: John Wiley \& Sons.

Rampangilei, W. (2016). Risiko Bencana Indonesia. Jakarta: BNPB.

Riandi, I. A. R. (2008). Upaya Antisipatif Perubahan Iklim dari Bidang Penataan Ruang (Catatan dari Poznan-Polandia, 1-12 Desember 2008). Bulletin Online Tata Ruang Edisi ke, 6.

Román-Rivera, M. A., \& Ellis, J. T. (2018). The King Tide Conundrum. Journal of Coastal Research, 34(4), 769-771. Doi: 10.2112/JCOASTRES-D-18A-00001.1

Saragih, S. O. (2014). Kota Pontianak Tergenang Banjir, Beritasatu.com. Retrieved from https://www.beritasatu.com/fabiolafebrinastri/nasional/204899/kotapontianak-tergenang-banjir

Timur, U. P. (2013). Urban Waterfront Regenerations Advances in Landscape Architecture
(http://dx.Doi.org/10.5772/55759 pp. 169206): INTECH.

UCLG. (2019). The Localization of the Global Agendas. Barcelona: United Cities and Local Governments.

United Nations. (2019). Sustainable Development Goal Report 2019. New York: United Nations.

Yusuf, M. A., Hayati, A., \& Faqih, M. (2018). Concept of Female Dormitory Bedrooms Based on Students'preference and Adaptation. Journal of architecture \& Environment, 17(2), 169-194. 